\title{
Fluorescein for vascular and oncological neurosurgery
}

\author{
Walter Stummer
}

Received: 13 May 2013 / Accepted: 15 May 2013 / Published online: 23 June 2013

(C) The Author(s) 2013. This article is published with open access at Springerlink.com

\section{Dear Sir:}

With interest, we have read the article by Roberto Rey-Dios and Aaron A. Cohen-Gadol: Technical principles and neurosurgical applications of fluorescein fluorescence using a microscope-integrated fluorescence module (Acta Neurochir. [2013] 155:701-706).

The authors explore new technology proffered by the Zeiss company, the YELLOW 560 system for neurosurgery using fluorescein.

The images obtained for vascular surgery appear impressive. In contrast to the Zeiss INFRARED 800 or FLOW 800 systems, which use indocyanine green (ICG), fluorescein is directly visible within the vessels, which the surgeon can inspect and directly manipulate. FLOW 800, on the other hand, gives an image only available on the screen of the microscope, but has the advantage of giving semiquantitative information that has been explored by our and other groups $[2,3]$.

Years ago, before we had access to the INFRARED 800 system, we used fluorescein for vascular surgery with the Zeiss Blue 400 system. This system gives violet blue illumination light $(375-440 \mathrm{~nm})$, and thus covers part of the excitation spectrum of fluorescein. The BLUE 400 emission filter effectively allows visualization of fluorescein, thus giving similar information to the YELLOW 560 system without additional costs to neurosurgeons with access to BLUE 400 technology (Fig. 1). Although the background is blue, the fluorescence is very vivid and the contrast of vasculature to brain very high, providing all the information one requires in vascular surgery. Surgeons may wish to explore this possibility.

On the other hand, we are somewhat worried about the reintroduction of fluorescein for oncological surgery, which our group abandoned many years ago, prior to the development of 5-ALA. The first description was in 1948 by Moore [4], who already commented that "edematous tissue does fluoresce, but to a lesser degree ".

Fluorescein enters the tumor via a broken down bloodbrain barrier and is unspecific. Wherever there is blood there will be fluorescein, especially in the zone of edema or in any areas of the brain with surgical injury. This is actually well illustrated by the authors' own images, $1 \mathrm{~d}$ and $1 \mathrm{e}$, and we wonder why these images are not commented on to this end. The image was obtained during surgery for a metastasis and clearly shows that fluorescence marks a much larger area of cortex adjacent to the metastasis in image $1 \mathrm{e}$ after surgical intervention, than in image $1 \mathrm{~d}$, and it appears this is related to surgical trauma. This was our personal experience many years ago. 


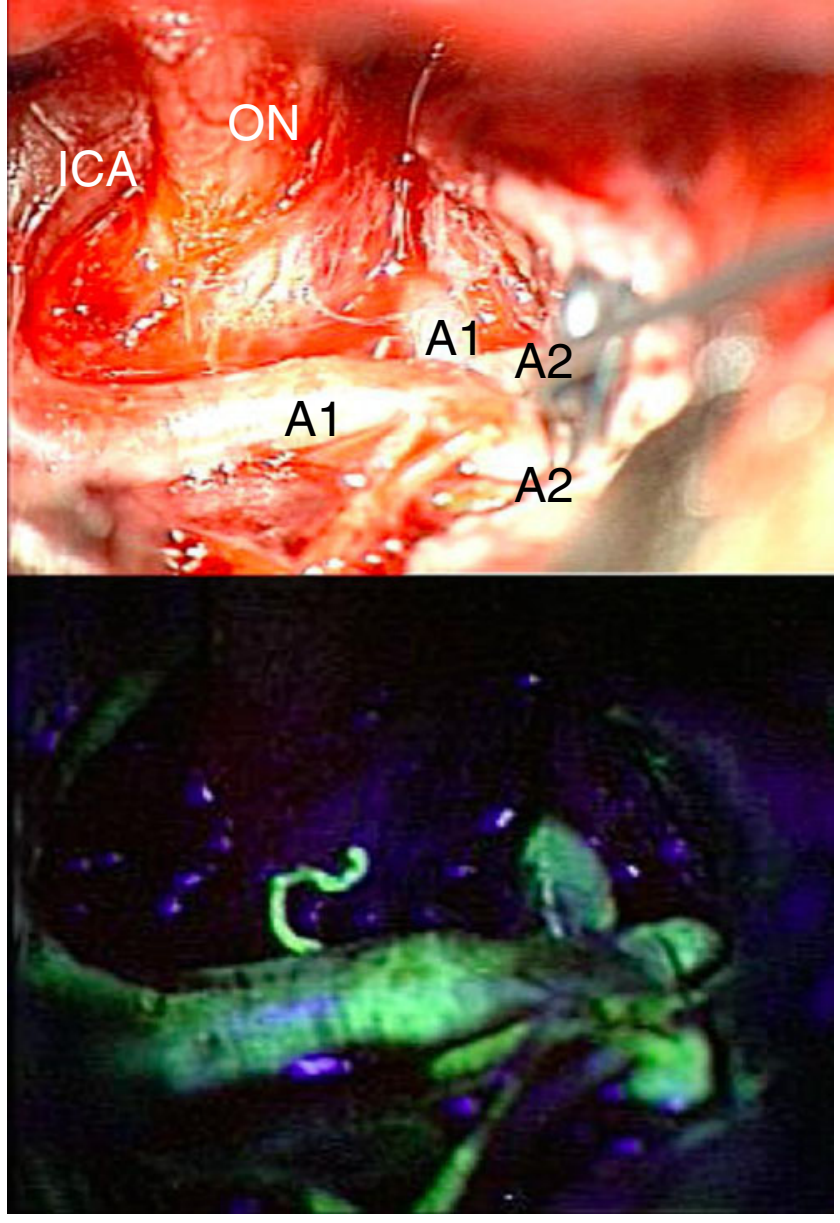

Fig. 1 Top: intra-operative imaging of anterior communicating artery aneurysm clipped via a left transorbital keyhole approach [1] (ICA internal carotid artery; A1, A2 A1 and A2-segments of the anterior cerebral arteries; ON optic nerve). Bottom: Same intra-operative site, observed using a single bolus injection of fluorescein. The patency of all vessels is clearly observed (Natrium-Fluorescein ${ }^{\circledR}$, Alcon, Germany, $2 \mathrm{ml}, 200 \mathrm{mg}$ )
We acknowledge greater ease of application of fluorescein, which needs only be injected, but if researchers would like to again follow this path, much work needs to be done regarding timing, dose, and most importantly, the positive predictive value of fluorescence. The investigation of the positive predictive value of fluorescence should focus on the end of surgery. At this stage, the most unspecific fluorescence will be expected as a consequence of tissue injury and leakage of fluorescein into adjacent tissue.

\section{Sincerely, \\ Walter Stummer, Münster}

\section{Conflicts of interest None.}

Open Access This article is distributed under the terms of the Creative Commons Attribution License which permits any use, distribution, and reproduction in any medium, provided the original author(s) and the source are credited.

\section{References}

1. Beseoglu K, Lodes S, Stummer W, Steiger HJ, Hänggi D (2004) The transorbital keyhole approach: early and long-term outcome analysis of approach-related morbidity and cosmetic results. Technical note. J Neurosurg 114:852-856

2. Holling M, Brokinkel B, Ewelt C, Fischer BR, Stummer W (2013) Dynamic ICG Fluorescence Provides Better Intra-operative Understanding of Arterio-venous Fistulas. Neurosurgery Jan 21; PMID: 23340337

3. Kamp MA, Slotty P, Turowski B, Etminan N, Steiger HJ, Hänggi D, Stummer W (2012) Microscope-integrated quantitative analysis of intraoperative indocyanine green fluorescence angiography for blood flow assessment: first experience in 30 patients. Neurosurgery 70:65-73

4. Moore GE, Peyton WT (1948) The clinical use of fluorescein in neurosurgery; the localization of brain tumors. J Neurosurg 5:392-398 